\title{
Oleic acid conjugated polymeric photosensitizer for metastatic cancer targeting in photodynamic therapy
}

\author{
Sanghee Lee and Kun $\mathrm{Na}^{*}$ (D)
}

\begin{abstract}
Background: Cancer has been conquered by recent advances in chemotherapy, targeted therapy, and their combinations. However, $90 \%$ of cancer patients die due to cancer recurrence or metastasis. Cancer cell change their metabolic properties to metastasize, changing from conventional glycometabolism to fat metabolism. This is because cancer cells are mainly spread through lymphatic system, which responsible for the absorption and transport of fatty acids and fats. Therefore, cancer cells ahead of metastasis specifically absorb fat to produce energy. Using this property, a photodynamic therapeutic agent conjugated with fatty acids (oleic acid, OA) capable of targeting metastatic cancer cells was developed.

Main body: Polymeric photosensitizer conjugated with OA were composed biocompatible polymers (pullulan) and photosensitizers (chlorin e6, Ce6) (OA-Pullulan-Ce6, OPuC). Pullulan consists of various repeated units, and it is possible to maximize the effects of $\mathrm{OA}$ and $\mathrm{Ce} 6$ by binding several them to one repeated unit. In this study, the interaction and detection potency of OPuC with cancer cells was confirmed using colon, breast, and lung cancer cell lines. In metastatic cancer cell, OPuC exhibited 3.27-fold higher cellular internalization than non-OA conjugated polymer (Pullulan-Ce6, PuC), however, in negative cell, the variation between OPuC and PuC was negligible despite the existence of OA (1.86-fold). OPuC accumulated in cancer cells could generate singlet oxygen under laser irradiation, resulting in cellular apoptosis and necrosis. Hereby, we proved that OA conjugated polymeric photosensitizer will be a potential metastatic cancer targeting photodynamic therapeutic agent.

Conclusion: Cancer cells actively receive OA conjugated polymeric photosensitizers for fat metabolic pathway, compared with normal cells. Therefore, a new type of polymeric photosensitizer using cancer metabolic properties has potency in metastatic cancer therapy.
\end{abstract}

Keywords: Photodynamic therapy, Photosensitizer, Cancer therapy, Metastasis cancer

\section{Background}

Cancer cell proliferation and invasiveness make it difficult to escape the risk from cancer recurrence or metastasis $[1,2]$. Metastatic cancer has a $90 \%$ mortality rate, because it is unclear why cancer spreads and their remedies in clinic [3-5]. Cancer metastasis refers to the dissemination of cancer cells from the primary tumor to other organs via the systemic circulation, specifically a sentinel lymph node [6-8]. Metastasis occurs both early and late stage in primary cancer through the lymphatic pathway, by invading

\footnotetext{
* Correspondence: kna6997@catholic.ac.kr

Department of Biotechnology, Department of Biomedical-Chemical

Engineering, Center for Photomedicine, The Catholic University of Korea, 43 Jibong-ro, Wonmi-gu, Bucheon-si, Gyeonggi-do 14662, South Korea
}

the barriers of nearby blood vessels and lymph node [4, 9]. And the lymph node microenvironment is different condition from the general cancer environment $[10,11]$.

Lymphatic system is responsible for absorption and transport of fatty acids and fats, so there are abundant lipids $[12,13]$. Cancer cells modify metabolic pathway in order to remain alive in lymph node environment. This phenomenon is similar with the characteristics that the metabolic change of cancer to aerobic glycolysis is a well-established marker of cancer [14-16]. To date, it is investigated that metastatic cancer alter their metabolic mechanisms to produce energy by consuming fat to survive in a fatty environment, against other characters that cancer cells generally use glucose as fuel $[16,17]$. Taking

(c) The Author(s). 2019 Open Access This article is distributed under the terms of the Creative Commons Attribution 4.0 International License (http://creativecommons.org/licenses/by/4.0/), which permits unrestricted use, distribution, and 
notice of these cancer cell properties, photosensitizers conjugated fatty acids have been developed, which can be expected to selectively kill metastatic cancer by photodynamic therapy (PDT).

PDT requires a photosensitizer (PS) and a light source with a specific wavelength corresponding to the activity of the PS [18, 19]. PS was accumulated in cellular membrane or intercellular. When intracellular PS was exposed to the specific wavelength, PS chemically react with light and oxygen, and produce a form of reactive oxygen species (ROS), such as singlet oxygen $\left({ }^{1} \mathrm{O}_{2}\right)$ and free radical at disease site. ROS oxidizes cells, causing cellular apoptosis and necrosis. Therefore, polymeric PS was accumulated in cancer cells, and the cells are killed by the generated ROS under laser irradiation. Targeting PSs have cytotoxicity only in PS-accumulated cells and do not damage normal cells without PS [20]. Therefore, cancer targeting PDT can reduce damage in normal tissues and effectively remove tumor as minimally invasive therapy. However, most PSs have some difficulties in clinical use, such as low solubility and low selectivity at disease sites [21].

To overcome these difficulties, conjugating various polymers or targeting moiety have been investigation [22]. Pullulan, a homogenous polysaccharide-based polymer consisting of maltotriose units produced by fungus Aureobasidium pullulans, is biodegradable, biocompatible, and soluble in organic solvents. So it has been developed for a drug carrier in the form of nanoparticles [23]. Pullulan has high molecular weight and consists of repeated units. Therefore, various materials can be conjugated at pullulan as a back bone. By conjugating numerous chlorin e6 (Ce6, a kind of PS) and oleic acid (OA, a kind of fatty acid) to large polymer (pullulan), it would be enabled that both PDT effect and targeting ability are more enhanced than single molecules.

In this study, OPuC was developed for inhibition of metastatic cancer proliferation using simple fatty acid. Firstly, we confirmed the physicochemical properties of $\mathrm{OPuC}$ and their singlet oxygen species generation effects. Also, we selected cancer cell lines, which have high metastasis risk, and then observed intercellular uptake and interaction with $\mathrm{OPuC}$. Finally, it is demonstrated that $\mathrm{OPuC}$ also can generate singlet oxygen in cytoplasm under laser irradiation. Metastatic cancer targeting PDT with $\mathrm{OPuC}$ induces cell death, and then their ability applied for all of cancer cells, compared with normal cells.

\section{Methods}

\section{Materials}

Pullulan (molecular weight (MW), $100 \mathrm{kDa}$ ) was purchased from Hayashobara (Okayama, Japan). Oleic acid (OA), 1,3dicyclohexylcarbodiimide (DCC), 4-dimethylaminopyri dine (DMAP), N-hydroxysuccinimide (NHS), dimethyl sulfoxide anhydrous (DMSO), 3-(4,5-dimethyl-2-thiazolyl)-2,5-diphenyl-2H-tetrazolium bromide (MTT) were purchased from Sigma-Aldrich Co. (St. Louis, MO, USA). Chlorin e6 (Ce6) was purchased from Frontier Scientific, Inc., (Salt Lake City, UT, USA). The dialysis membrane (molecular weight cutoff (MWCO), $3.5 \mathrm{kDa}$ ) was purchased from Spectrum Laboratories, Inc. (Rancho Dominguez, CA, USA). Singlet Oxygen Sensor Green (SOSG) was purchased from Molecular Probes (Eugene, OR, USA). The ${ }^{1} \mathrm{H}-\mathrm{NMR}$ spectra were recorded using a Bruker NMR Spectrometer $(300 \mathrm{MHz})$.

\section{Synthesis and characterization of OPuC}

The conjugation of Pullulan-Ce6 $(\mathrm{PuC})$ was performed via DCC/DMAP mediated esterification as previously reported by our group [24]. Briefly, pullulan (100 mg, 21 $\mathrm{mM})$ was completely dissolved in DMSO $(10 \mathrm{~mL})$ with DMAP (35.7 mg, $292 \mu M_{-} 1.2$ fold Ce6 in moles). And then, both Ce6 $(69.8 \mathrm{mg}, 117 \mu \mathrm{M})$ and DCC $(29.0 \mathrm{mg}$, $140 \mu M_{-} 1.2$ fold Ce6 in moles) are dissolved in DMSO were added to the pre-dissolved pullulan solution and stirred for $48 \mathrm{~h}$ at room temperature (RT). After filtration $0.45 \mu \mathrm{m}$ membrane filtration, the solutions were purified by precipitation in ether $(250 \mathrm{~mL})$ three times and then dried in vacuo. To remove remained ether, carried out lyophilization with little water.

Synthesis of OA-Pullulan was preceded to synthesize OPuC. Firstly, pullulan $(200 \mathrm{mg}, 41 \mathrm{mM})$, and DMAP (7.1 mg, $6 \mathrm{mM}_{-}$1.2-fold $\mathrm{Oa}$ in moles) were dissolved in DMSO $(10 \mathrm{~mL})$. OA $(165.2 \mathrm{mg}, 585 \mathrm{mM})$ and DCC (144.8 mg, $700 \mu M_{-}$1.2-fold OA in moles) were dissolved in DMSO $(1 \mathrm{~mL})$. Both the pullulan and OA solutions were mixed together, followed by stirring for $48 \mathrm{~h}$ at RT. After reaction, the solution was purified by precipitation and vacuo. To conjugate $\mathrm{Ce} 6$ with $\mathrm{OA}$ Pullulan, OA-Pullulan (100 mg), DMAP (1.3 mg, $1 \mathrm{mM}$ ), Ce6 (64.8 mg, $11 \mathrm{mM})$, and DCC (26.9 mg, $13 \mathrm{mM})$ were completely dissolved in DMSO $10 \mathrm{~mL}$. After $48 \mathrm{~h}$ reaction time, the final solution was purified in the same way as the described method of purifying PuC. The synthesis of $\mathrm{PuC}$ and $\mathrm{OPuC}$ were evaluated by recording the ${ }^{1} \mathrm{H}-\mathrm{NMR}$ spectra through a Bruker NMR Spectrometer (Bruker, Germany). Zeta potential of OPuC was measured using dynamic light scattering (DLS, Zetasizer Nano ZS (Malvern Instruments, Malvern, UK) in DI water.

\section{Singlet oxygen generation efficacy of OPuC}

To measure the singlet oxygen generation efficacy of $\mathrm{OPuC}$, singlet oxygen sensor green (SOSG) solution $(10 \mu \mathrm{M})$ was mixed with $1 \mathrm{~mL}$ of free $\mathrm{Ce} 6$ and $\mathrm{OPuC}$ at $10 \mu \mathrm{g} \mathrm{mL}^{-1}$ of Ce6 equivalent. The absorbance of samples was analyzed by UV-vis spectroscopy (UV-2450, Shimadzu, Japan) to quantify of $\mathrm{Ce} 6$ concentrations at $664 \mathrm{~nm}$ wavelength. Each sample was irradiated with $20 \mathrm{~mW} \mathrm{\textrm {cm } ^ { - 2 }}$ of a $670 \mathrm{~nm}$ laser 
source (Fiber Coupled Laser Modules, LaserLab, Seoul, Korea) for $200 \mathrm{~s}$. The fluorescence intensity of SOSG ( $\lambda$ ex = $504 \mathrm{~nm}, \lambda e m=525 \mathrm{~nm}$ ) was detected using fluorescence spectroscopy (RF-5301, Shimadzu, Japan).

\section{Cell culture and incubation conditions}

Fetal bovine serum (FBS), antibiotics (penicillin/ streptomycin), and Dulbecco's phosphate buffered saline (DPBS) were purchased from Gibco BRL (Invitrogen Corp., Carlsbad, CA, USA). L929 cells (mouse connective tissue normal cell line, KCLB no.10001), A549 (human lung carcinoma cell line, KCLB no.10185), PANC-1 (human pancreas carcinoma cell lines, KCLB no.21469), and HCT116 (human colon carcinoma cell line, KCLB no.10247) were obtained from the Korean Cell Line Bank (KCLB). L929, PANC-1 cells were cultured in DMEM (Dulbecco Modified Eagle Medium) and A549, HCT116 cells were cultured in RPMI 1640 (Roswell Park memorial Institute 1640 Medium) supplemented with $10 \% \mathrm{FBS}$ and $1 \%$ penicillin/ streptomycin. Cells were cultured at $37^{\circ} \mathrm{C}$ in $5 \% \mathrm{CO}_{2}$ and changed fresh medium every 2 to 3 days. $\mathrm{PuC}$ and $\mathrm{OPuC}$ were dissolved in DMSO and diluted in serum-free (SF) medium until the DMSO concentration reached under $0.1 \%$. All reported concentrations referred to free $\mathrm{Ce} 6$ equivalents. Untreated cells were kept in the dark and used as a reference standard.

\section{In vitro cellular uptake of OPuC}

To observe the cellular uptake of $\mathrm{OPuC}$, flow cytometry and confocal laser scanning microscope (CLSM) were carried out. Different type of cells $\left(1.0 \times 10^{5}\right.$ cells/well in a 12-well plates) were incubated with $\mathrm{PuC}$ or $\mathrm{OPuC}$ (Ce6 conc. $5 \mu \mathrm{g} \mathrm{mL}^{-1}$ ) for $4 \mathrm{~h}$ at $37^{\circ} \mathrm{C}$. Cells were washed three times, harvested with DPBS, and transferred to FACS tubes. All samples were analyzed by a

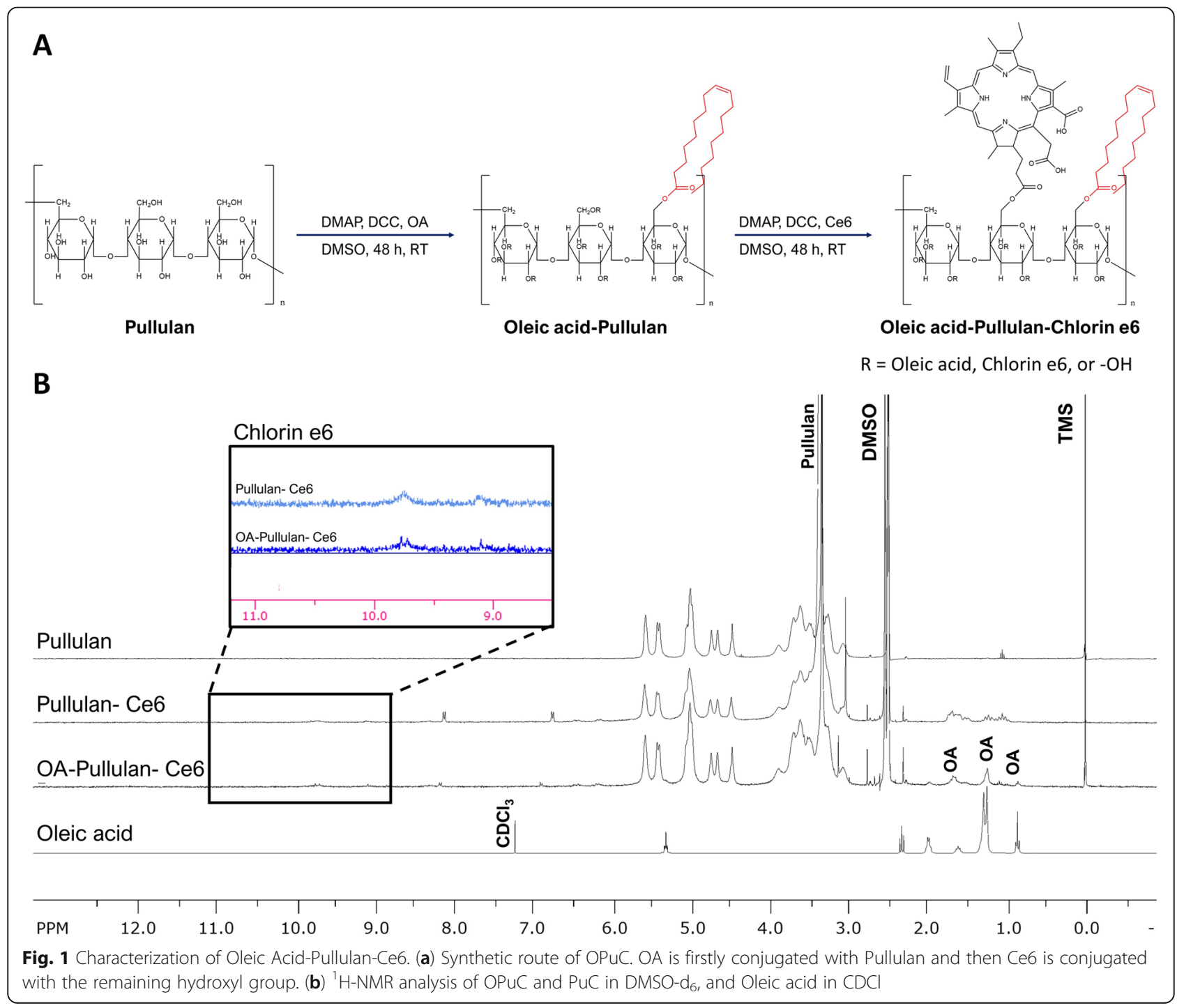


Becton-Dickinson FACS CantoII (San Jose, CA, U.S.A). For each sample, 10,000 cells (gated events) were counted, and Ce6 fluorescence was detected with logarithmic settings (APC (Ce6), $\lambda e m=675 \mathrm{~nm}$ ). Each experiment was analyzed statistically using FACS Diva software (BD).

L929 and HCT116 cells were grown at a density of $1.0 \times 10^{5}$ cells/well on $25 \mathrm{~mm}$ sterile round shape cover glasses inserted in a 6 well plate at $37^{\circ} \mathrm{C}$ for $18 \mathrm{~h}$. SFmedia containing $\mathrm{PuC}$ or $\mathrm{OPuC}$ (equivalent to $\mathrm{Ce} 6$ conc. $5 \mu \mathrm{g} \mathrm{mL}^{-1}$ ) was added, and cells were incubated for $4 \mathrm{~h}$. After the incubation medium was removed, cells were washed with DPBS, fixed for 10 min with $4 \%$ paraformaldehyde solution at room temperature, and stained with 4,6-diamidino-2-phenylindole (DAPI $1 \mu \mathrm{L}, 3.63 \mathrm{mM}$ ) for $2 \mathrm{~min}$. After washing, the cover glasses were placed onto slides for imaging with a confocal laser scanning microscope (CLSM, LSM 710 Meta, Carl Zeiss, Germany). Fluorescent images were analyze using the LSM Image Browser software (Carl Zeiss, Germany).

In vitro phototoxicity of OPC

A549, PANC-1, HCT116, and L929 cells $\left(2 \times 10^{4}\right.$ cells/ well in 48-well plates) were incubated with $\mathrm{PC}$ or $\mathrm{OPuC}$ $\left(0.10,0.25,0.50,0.75,1.00,1.50\right.$, or $2.00 \mu \mathrm{gL}^{-1}$ of Ce6) for $4 \mathrm{~h}$ at $37^{\circ} \mathrm{C}$. After the incubation, the media were replaced with a fresh culture medium. Cells were irradiated with a $670 \mathrm{~nm}$ laser source $\left(1 \mathrm{~J} \mathrm{~cm}^{-2}\right)$ and then incubated for $24 \mathrm{~h}$. The MTT solution $\left(1 \mathrm{mg} \mathrm{mL}^{-1}\right)$ was added to each well and incubation for $3 \mathrm{~h}$, followed by replacement with DMSO. The absorbance of the MTT dye at $570 \mathrm{~nm}$ was measured using a microplate reader (Bio-Tek, VT, USA) to determine cell viability.

\section{Statistical analysis}

Experimental Data are presented as mean \pm standard error of the mean for results obtained from three independent trials unless otherwise indicated. The statistical significance was determined using one-way analysis with $p$-values $<0.05$ as the level of significance. $(* p<0.05$, $\because * p<0.01, * * * p<0.001)$.

\section{Results}

Synthesis and characterization of OPuC

The synthesized $\mathrm{OPuC}$ was analyzed by ${ }^{1} \mathrm{H}-\mathrm{NMR}$ and quantified the concentration of $\mathrm{Ce} 6$ via UV-vis spectrometer. Peak of ${ }^{1} \mathrm{H}-\mathrm{NMR}$ showed conjugated $\mathrm{Ce} 6$ on $\mathrm{PuC}$ and $\mathrm{OPuC}$, and then the $\mathrm{OPuC}$ spectra contained the peak of OA (Fig. 1b). Despite pullulan had neutral net charge, $\mathrm{OPuC}$ had slightly anion charge by conjugating $\mathrm{OA}$ and $\mathrm{Ce} 6$, containing carboxyl groups (Fig. 2a). Further, ROS generation efficiency of the OPuC was confirmed in aqueous condition using the singlet oxygen sensor green (SOSG). Fluorescence intensity of SOSG

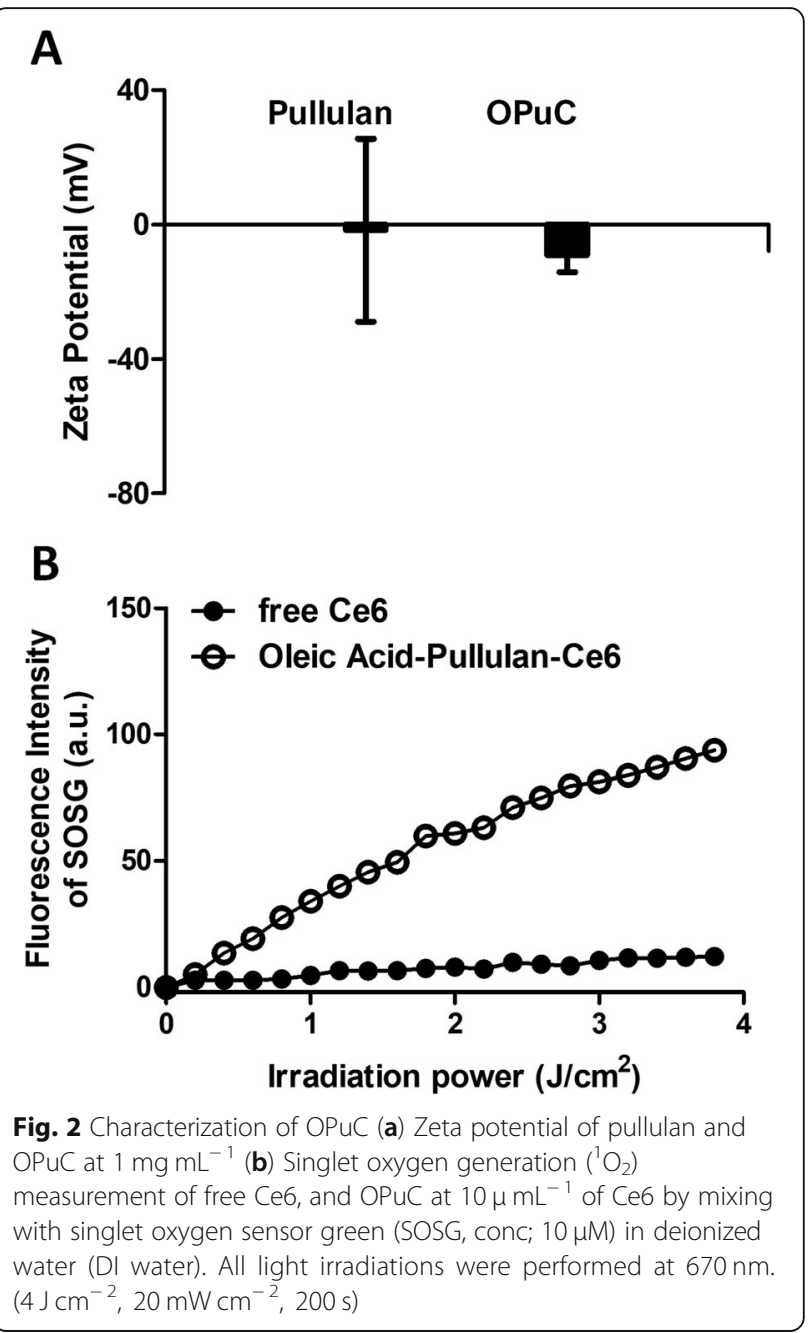

on free Ce6 did not show meaningful increase, however, $\mathrm{OPuC}$ effectively produced ROS depending on laser irradiation time (Fig. 2b). This is because, free Ce6 did not dissolve but rather aggregated in aqueous condition, occurring quenching fluorescence intensity due to $\pi-\pi$ interactions. However, the $\mathrm{OPuC}$ enhance their solubility in water, so that successfully generated ROS.

\section{Interaction of OPuC with cancer cells}

Cancer cells prepare metastasis to other organs by modifying their metabolic properties, consuming fatty acid as fuel. To determine the affinity between OA and cancer cells, cell internalization of $\mathrm{OPuC}$ was analyzed by flow cytometry in cancer cell lines that are known to be well metastasized, such as lung (A549), pancreas (PANC-1), colon cancer (HCT116) (Fig. 3b). And the fluorescence intensity of $\mathrm{Ce} 6$ in cytoplasm was quantified and presented in a bar graph (Fig. 3b). Overall, the Ce6 fluorescence intensity in $\mathrm{OPuC}$-treated cancer cells was significantly increased, compared with PuC-treated cancer cells. However, there was no meaningful difference 


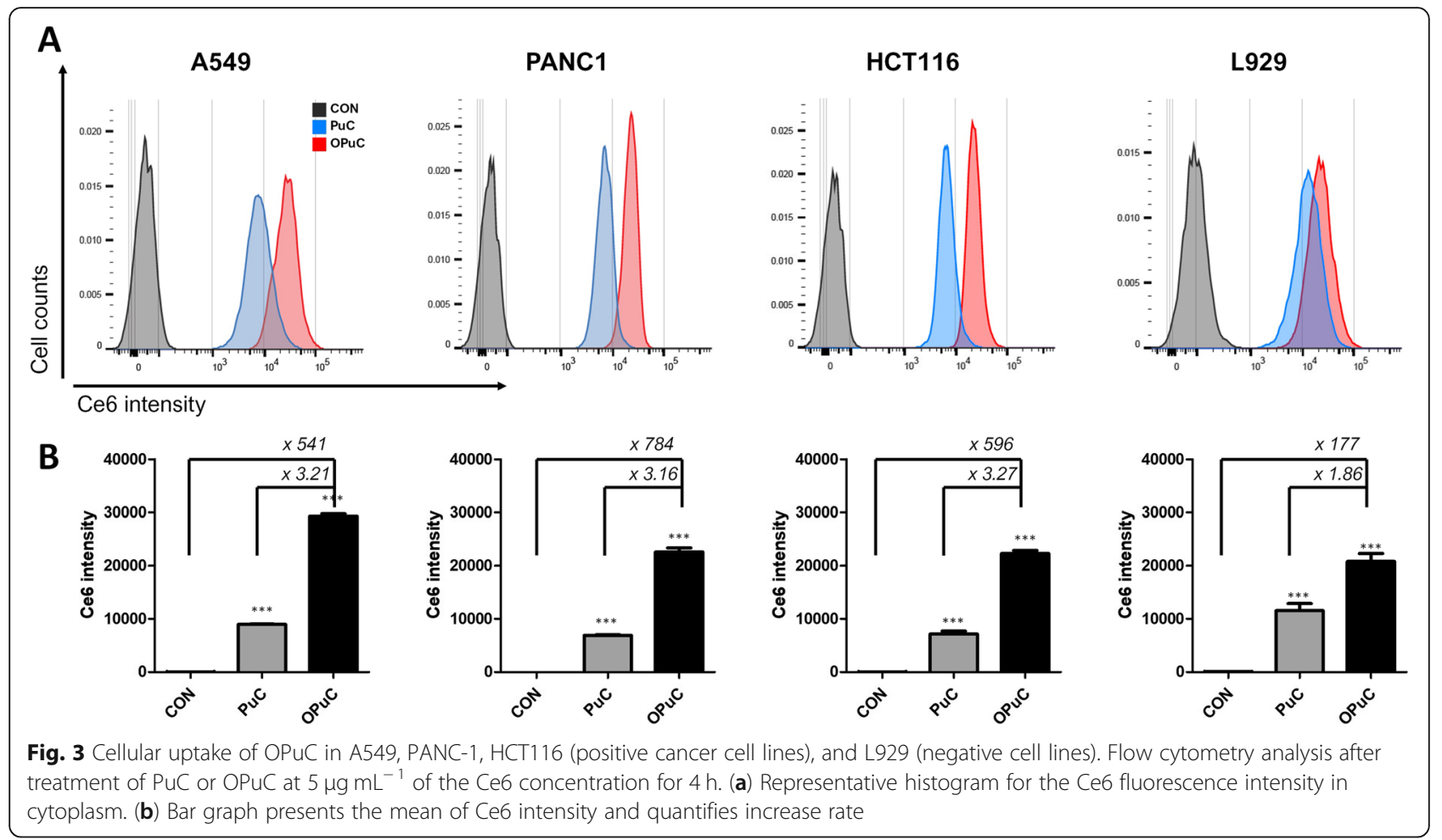

in L929 (normal cell, mouse fibroblast) that were incubated with $\mathrm{PuC}$ or $\mathrm{OPuC}$. The fluorescence intensity of OPuC-treated HCT116 cells raised around 3.27-fold more than PuC-treated, but L929 cells increased 1.86fold, which means L929 had non-specific interaction with $\mathrm{OA}$ by hydrophobic interaction.
To visualize the targeting ability of $\mathrm{OPuC}$, both HCT116 cells (positive cell lines, Fig. 4a) and L929 (negative cell lines, Fig. 4b) were incubated with $\mathrm{PuC}$ or $\mathrm{OPuC}$ and observed via CLSM. Like flow cytometry data, $\mathrm{OPuC}$ was efficiently absorbed into cells than $\mathrm{PuC}$. Interestingly, images of HCT116 cells treated OPuC

\section{A}

HCT116 (colon cancer cells)

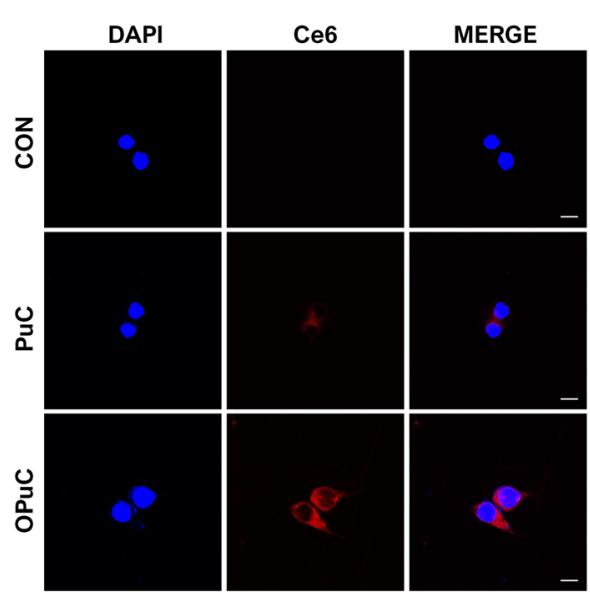

B L929 (normal cells)

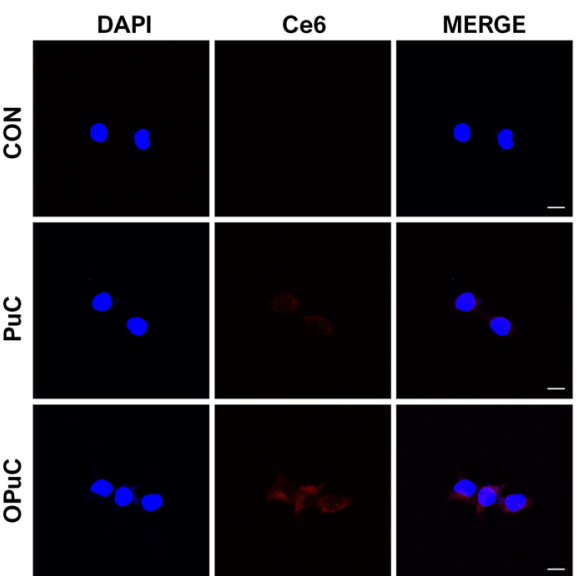

Fig. 4 Cellular uptake of OPuC by Confocal Laser Scanning Microscopy images in HCT116 (a, positive cell line) and L929 (b, negative cell line) after treatment PuC or OPuC ( $5 \mathrm{mg} \mathrm{mL}^{-1}$ of Ce6) for $4 \mathrm{~h}$. Nucleus were stained DAPI (blue) and accumulated intracellular PuC or OPuC were brighten red. Merge images present the interaction with cells. The scale bar is $10 \mu \mathrm{m}$ 


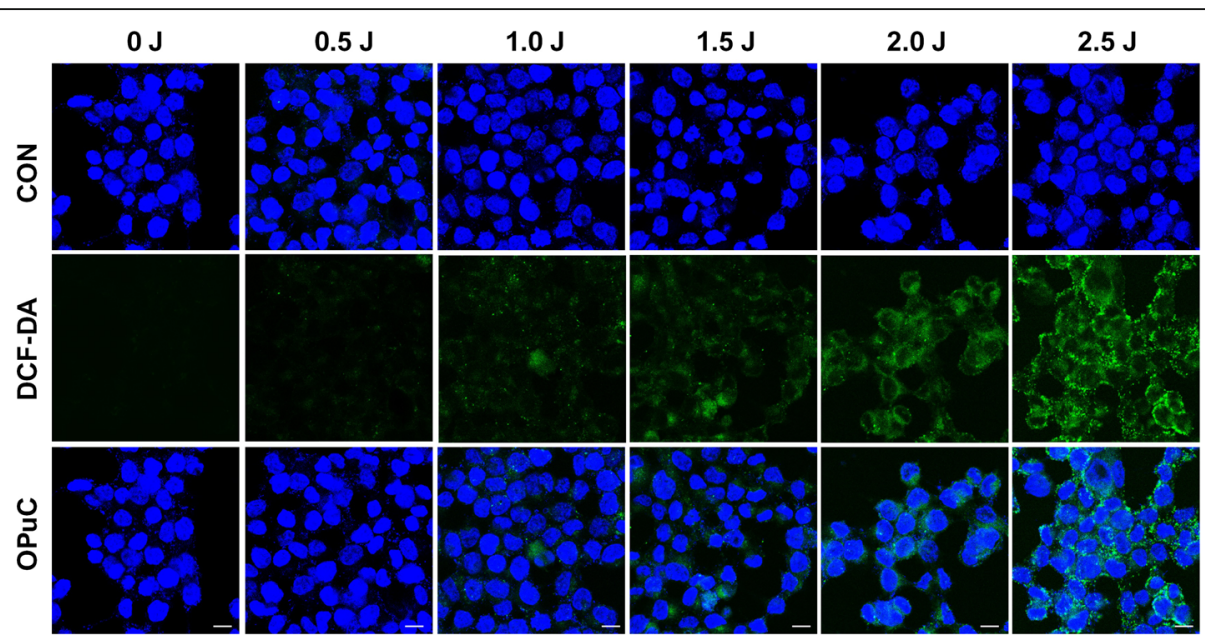

Fig. 5 Intracellular ROS generation of OPuC. Fluorescence microscopic images of HCT116 cells after treatment OPuC (2 $\mu \mathrm{g} \mathrm{mL} \mathrm{L}^{-1}$ of Ce6) for $4 \mathrm{~h}$ to detect ROS type ${ }_{1}$ (DCF-DA, conc $2.5 \mu \mathrm{M}$ ) depending on increase of laser powers. The scale bar is $10 \mu \mathrm{m}$

significantly brighter than those of L929 cells, but PuC images had no meaningful difference in two cells.

\section{Intracellular ROS generation of OPuC}

$\mathrm{OPuC}$ can be generated ROS intracellular condition to induce cell death. DCF-DA penetrated live cell membrane is oxidized and emits luminous green fluorescence in the presence of non-specific ROS. So, we confirmed ROS generation via DCF-DA, and determined a potency of PDT (Fig. 5). In case of HCT116 cells, cells fully incubated with the same concentration with $\mathrm{OPuC}$ and irradiated laser at various laser power, emitting strong green fluorescence. The fluorescence intensity was gradually increased depending on laser power. The strong laser intensity allows the PSs to better form ROS by chemical reactions of light and oxygen, which directly related to cell death.

\section{Phototoxicity of OPuC reflects the targeted therapy}

With confirming cancer cell specific uptake of OPuC and singlet oxygen generation, we finally demonstrated the relation of cancer cell death using MTT assay (Fig. 6).
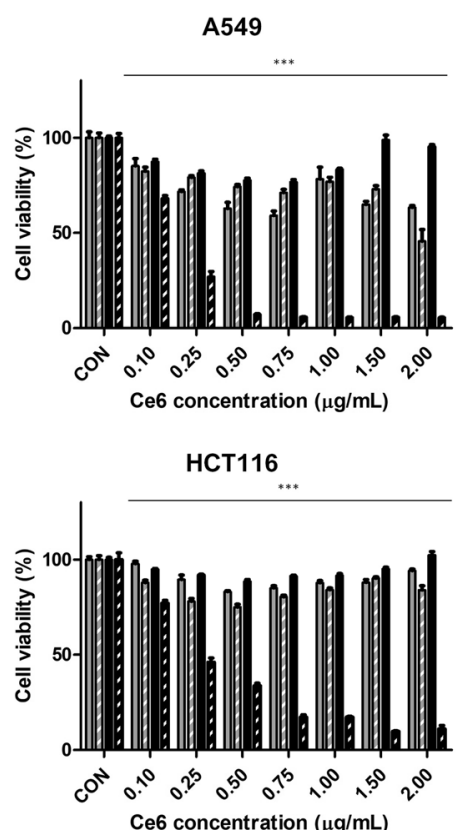

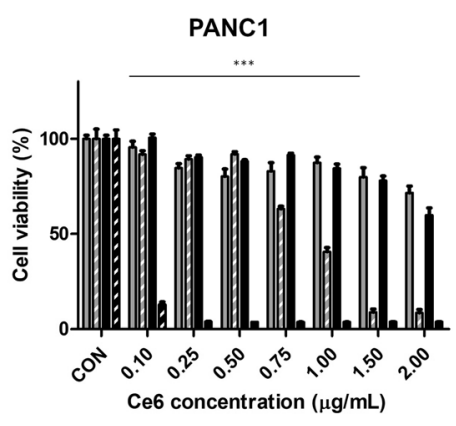

L929

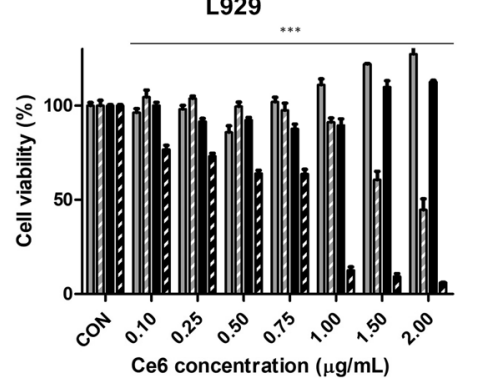

$\square$ PuC Laser (-)

$\square$ PuC Laser (+)

OPuC Laser (-)

OPuC Laser (+)

Fig. 6 In vitro cancer cell specific phototoxicity of OPuC. MTT assay at various concentration of Ce6 under laser irradiation of $1 \mathrm{~J} \mathrm{~cm}{ }^{-2}(10 \mathrm{~mW}$ $\mathrm{cm}^{-2}, 100 \mathrm{~s}$ ) in A549 (lung cancer), PANC-1 (pancreatic cancer), HCT116 (colon cancer), and L929 (normal fibroblast 
Cancer cell death was caused by PDT upon laser irradiation in the specific wavelength range. So, we incubated cells with $\mathrm{PuC}$ or $\mathrm{OPuC}$, subsequently irradiating laser at $670 \mathrm{~nm}$. As shown Fig. 6, PuC and $\mathrm{OPuC}$ without laser groups did not induce cell death in all cell lines, however, cell viability was dramatically decrease in both $\mathrm{PuC}$ and $\mathrm{OPuC}$ with laser groups. Focusing on $\mathrm{OPuC}$ with laser in cancer cell lines (A549, PANC-1, and HCT116), cell death indicated at $0.1 \mu \mathrm{g} \mathrm{mL}^{-1} \mathrm{Ce} 6$ concentration of $\mathrm{OPuC}$, and then cell viability gradually decreased depending on the increase of $\mathrm{Ce} 6$ concentration. However, in L929 cells, it was confirmed that cell viability was maintained up to $0.75 \mu \mathrm{g} \mathrm{mL}^{-1} \mathrm{Ce} 6$ concentration of $\mathrm{OPuC}$. Based on the analysis of flow cytometry and confocal images, cancer cell absorbed more OPuC under the same conditions, which showed stronger phototoxicity under irradiated same power laser. However, normal cells showed low sensitivity to phototoxicity of OPuC.

\section{Discussion}

Cancer cell was changed every condition to rapidly proliferate. Metastatic cancer modifies their metabolic mechanism to survive in lymphatic system. So, we kept an eye on this cancer's properties, developing metastatic cancer targeting PDT agents. Fat conjugated PS (OAPullulan-Ce6, OPuC) were developed using the properties of metastatic cancers that ingested fat. Free Ce6 have low solubility in water and low specificity at disease sites. However, Pullulan enhanced the solubility of PS, decreasing the fluorescence quenching effects. Thus, OPuC fulfill the PS's ability in body fluidic conditions, so it can be utilized as a therapeutic agent for targeted PDT.

The synthesized OPuC was specifically accumulated in cancer cells, and successfully generated effective ROS. Intracellular ROS was enhanced in the laser dependent manners, and eventually induced cell death. In the phototoxicity of $\mathrm{OPuC}$ with laser at $0.50 \mu \mathrm{g} \mathrm{mL}^{-1}$ of $\mathrm{Ce} 6$, the survival rate was $7.07 \%$ in A549, 3.61\% in PANC-1, and $33.48 \%$ in HCT116 (cancer cell, positive cell). But the survival rate was $64.0 \%$ in L929 (normal cell, negative cell) at the same concentration of Ce6. We can conclude that $\mathrm{OPuC}$ has specific interactions with cancer cells originated from other organs. Thus, OPuC deserve much consideration on the applicability of metastatic cancer PDT.

\section{Conclusions}

In previous studies, the special characters of metabolic pathway in metastatic cancer provided clues that targeted metastatic cancer therapy may be possible. We applicated this discovery in PDT and have developed a method to specifically kill metastatic cancer cells. We designed $\mathrm{OPuC}$ to target metastatic cancer using their metabolic properties consuming fatty acids. A variety of cancer cells were effectively detected and interacted with $\mathrm{OPuC}$ due to fatty acid (i.e., Oleic acid). Further, low concentration of $\mathrm{OPuC}$ successfully caused cancer cell death through ROS generation upon laser in vitro. In order to utilize our study in clinic, therapeutic effects will be maximized when the premise that cancer cell have metastatic properties. Moreover, they must precede that $\mathrm{OPuC}$ is accumulated into cancer cells in cancer patient as well as it is effective enough to prevent metastasis. However, an approach of cancer therapy using metabolic feature is quite meaningful.

\section{Abbreviations \\ DCF-DA: 2', 7`-Dichlorofluorescein diacetate; OPuC: Oleic acid-Pullulan-Ce6; PDT: Photodynamic therapy; PS: Photosensitizer; PuC: Pullulan-Ce6; ROS: Reactive oxygen species; SOSG: Singlet oxygen sensor green \\ Acknowledgements \\ This work was supported by the Strategic Research through the National Research Foundation of Korea (NRF) grant funded by the Korean government (MSIP) (NRF-2017R1A2B3010038).}

Availability of data and materials

Data sharing is not applicable to this review article.

Authors' contributions

Both authors wrote and revised the manuscript. Both authors read and approved the final manuscript.

\section{Funding}

This work was supported by the Strategic Research through the National Research Foundation of Korea (NRF) grant funded by the Korean government (MSIP) (NRF-2017R1A2B3010038).

Ethics approval and consent to participate Not applicable.

\section{Consent for publication}

Not applicable.

\section{Competing interests}

The authors declare that they have no competing interests.

Received: 10 October 2019 Accepted: 27 November 2019

Published online: 03 January 2020

\section{References}

1. Green JA, Kirwan JM, Tierney JF, Symonds P, Fresco L, Collingwood M, Williams CJ. Survival and recurrence after concomitant chemotherapy and radiotherapy for cancer of the uterine cervix: a systematic review and metaanalysis. Lancet. 2001;358(9284):781-6.

2. Cooper JS, Pajak TF, Forastiere AA, Jacobs J, Campbell BH, Saxman SB, Kish JA, Kim HE, Cmelak AJ, Rotman M. Postoperative concurrent radiotherapy and chemotherapy for high-risk squamous-cell carcinoma of the head and neck. N Engl J Med. 2004;350(19):1937-44.

3. Schroeder A, Heller DA, Winslow MM, Dahlman JE, Pratt GW, Langer R, Jacks T, Anderson DG. Treating metastatic cancer with nanotechnology. Nat Rev Cancer. 2012;12(1):39.

4. Massagué J, Obenauf AC. Metastatic colonization by circulating tumour cells. Nature. 2016:529(7586):298.

5. Quail DF, Joyce JA. Microenvironmental regulation of tumor progression and metastasis. Nat Med. 2013;19(11):1423.

6. Steeg PS. Targeting metastasis. Nat Rev Cancer. 2016;16(4):201.

7. Lambert AW, Pattabiraman DR, Weinberg RA. Emerging biological principles of metastasis. Cell. 2017;168(4):670-91.

8. Harper KL, Sosa MS, Entenberg D, Hosseini H, Cheung JF, Nobre R, AvivarValderas A, Nagi C, Girnius N, Davis RJ. Mechanism of early dissemination and metastasis in Her2+ mammary cancer. Nature. 2016;540(7634):588. 
9. Valastyan S, Weinberg RA. Tumor metastasis: molecular insights and evolving paradigms. Cell. 2011;147(2):275-92.

10. Pereira ER, Jones D, Jung K, Padera TP: The lymph node microenvironment and its role in the progression of metastatic cancer. In: Seminars in cell \& developmental biology: 2015. Elsevier: 98-105.

11. Kawada K, Taketo MM. Significance and mechanism of lymph node metastasis in cancer progression. Cancer Res. 2011;71(4):1214-8.

12. Charman W, Stella V. Transport of lipophilic molecules by the intestinal lymphatic system. Adv Drug Deliv Rev. 1991;7(1):1-14.

13. Guan D, Xiong Y, Borck PC, Jang C, Doulias P-T, Papazyan R, Fang B, Jiang C, Zhang Y, Briggs ER: Diet-induced circadian enhancer remodeling synchronizes opposing hepatic lipid metabolic processes. Cell 2018;174(4): 831-842. e812.

14. Hanahan D, Weinberg RA: Hallmarks of cancer: the next generation. cell 2011:144(5):646-674.

15. Hensley CT, Wasti AT, DeBerardinis RJ. Glutamine and cancer: cell biology, physiology, and clinical opportunities. J Clin Invest. 2013;123(9):3678-84.

16. Loo JM, Scherl A, Nguyen A, Man FY, Weinberg E, Zeng Z, Saltz L, Paty PB, Tavazoie SF. Extracellular metabolic energetics can promote cancer progression. Cell. 2015;160(3):393-406.

17. Lee C-k, Jeong S-h, Jang C, Bae H, Kim YH, Park I, Kim SK, Koh GY. Tumor metastasis to lymph nodes requires YAP-dependent metabolic adaptation. Science. 2019;363(6427):644-9.

18. Dolmans DE, Fukumura D, Jain RK. Photodynamic therapy for cancer. Nat Rev Cancer. 2003;3(5):380.

19. Vrouenraets MB, Visser G, Snow GB. Basic principles, applications in oncology and improved selectivity of photodynamic therapy. Anticancer Res. 2003;23(1B):505-22.

20. Henderson BW, Dougherty TJ. How does photodynamic therapy work? Photochem Photobiol. 1992;55(1):145-57.

21. Hackbarth S, Horneffer V, Wiehe A, Hillenkamp F, Röder B. Photophysical properties of pheophorbide-a-substituted diaminobutane poly-propyleneimine dendrimer. Chem Phys. 2001;269(1-3):339-46.

22. Shin H, Na K. In situ vaccination with biocompatibility controllable immunosensitizer inducing antitumor immunity. Biomaterials. 2019;197:32-40.

23. Tong Q, Xiao Q, Lim L-T. Preparation and properties of pullulan-alginatecarboxymethylcellulose blend films. Food Res Int. 2008;41(10):1007-14.

24. Bae B-c, Li F, Ling D, Na K. Self-organized nanogel from pullulan/ pheophorbide-a conjugate as a macromolecular photodynamic agent. J Porphyrins Phthalocyanines. 2010;14(10):851-8.

\section{Publisher's Note}

Springer Nature remains neutral with regard to jurisdictional claims in published maps and institutional affiliations.

Ready to submit your research? Choose BMC and benefit from:

- fast, convenient online submission

- thorough peer review by experienced researchers in your field

- rapid publication on acceptance

- support for research data, including large and complex data types

- gold Open Access which fosters wider collaboration and increased citations

- maximum visibility for your research: over $100 \mathrm{M}$ website views per year

At $\mathrm{BMC}$, research is always in progress.

Learn more biomedcentral.com/submissions 